\title{
FEASIBILITY STUDIES OF AN ACCELERATOR FOR THE INTENSE PULSED NEUTRON SOURCE (IPNS)
}

\author{
by
}

Tat K. Khoe and Motoharu Kimura

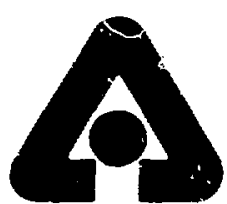

ARGONPE NATIONAL LABORATORY, ARGONNE, ILLINOIS

Prepared for the U. S. ENERGY RESEARCH

AND DEVELOPMENT ADMINISTRATION

under Contract W-31-109-Eng-38 
The facilities of Argonne National Laboratory are owned by the United States Government. Under the terms of a contract (W-31-109-Eng-38) between the U. S. Energy Research and Development Administration, Argonne Universities Association and The University of Chicago, the University employs the staff and operates the Laboratory in accordance with policies and programe formulated, approved and reviewed by the Association.

\section{MEMBERS OF ARGONNE UNIVERSITIES ASSOCIATION}

The University of Arizona Carnegie-Mellon University Case Western Reserve University The University of Chicago University of Cincinnati Illinois Institute of Technology University of Illinois Indiana University Iowa State University The University of Iowa
Kansas State Univeraity The Univeraity of Kansas Loyola University Marquette University Michigan State University The University of Michigan University of Minnesota University of Missouri Northwestern University University of Notre Dame
The Ohio State Univeraity

Ohio Univeraity

The Penneylvania State University

Purdue University

Saint Louis University

Southern Illinoiv University

The University of Texas at Austin

Washington University

Wayne State University

The University of Wisconsin

This report was prepared as an account of work sponsored by the United States Government. Neither the United States nor the United States Energy Research and Development Administration, nor any of their employees, nor any of their contractros, subcontractors, or their employees, makes any warranty, express or implied, or assumes any legal liability or responsibility for the accuracy: completeness or usefulness of any information, apparatus, product or process disclosed, or represents that its use would not infringe privately-owned rights. Mention of commercial products, their manufacturers, or their suppliers in this publication does not imply or conmete approva! or disapproval of the product by Argonne Naticnal Laboratory or the U. S. Energy Research and Developmer.i Administration. 


\section{ARGONNE NATIONAL LABORATORY \\ 9700 South Cass Avenue \\ Argonne, Illinois 60439}

FEASIBTLITY STUDIES OF AN ACCELERATOR

FOR THE INTENSE PULSED NEUTRON SOURCE (IPNS)

by

Tat K. Khoe

Accelerator Research Facilities Division

and

Motoharu Kimura

Solid State Science Division

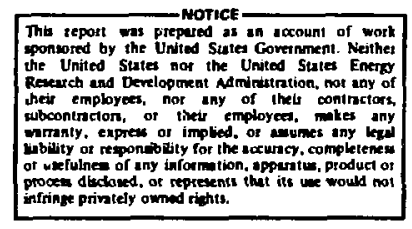

November 1974

WSTRIBUTION OF THIS DUCUIENT IS UNLIMITEE 
I. Introduction . . . . . . . . . . . . . . . 1

II. General Layout of ZING and IPNS Fac1lity ........ 1

III. Required Specifications for the IPNS . . . . . . . 2

IV. Some Considerations on Possible Systems Other

than that Proposed in thit Report . . . . . . . . . 3

(a) ZING-Fission Neutron Multiplication System . . . 3

(b) Some Other Accelerators, etc. . . . . . . 4

V. Proposed $\mathrm{H}^{-}$LInac-Proton Synchrotron System ...... 5

(a) Neutron Producing Target and the Choice of Acceleration . . . . . . . . . . . . 5

(b) Intensity Limitations in the Synchrotron ... . 10

(c) Choice of the Synchrotron Lattice Structure . . 14

(d) Choice of Injection Method $\left(\mathrm{H}^{-}\right.$versus $\mathrm{H}^{+}$) and the Injection Energy . . . . . . . . . 16

(e) Injection and Extraction Methods........ 17

(f) Magnet and Vacuum System ........... 18

(g) Accelerating System . . . . . . . . . 19

VI. Shielding and Transport Systems . . . . . . . . 22

Table of Accelerator Parameters . . . . . . . 24 Acknowl edgment . . . . . . . . . . . . 25

References.................. 25 


\section{LIST OF FIGURES}

Fig. No.

Page

1 Conceptual target and moderator assembly.

2 Radial and axial distribution of the production of evaporation neutrons in a $7.5 \mathrm{~cm}$ radius, $30 \mathrm{~cm}$ long $\mathrm{U}^{238}$ target with $800 \mathrm{MeV}$ protons incident on axis (LASL Report LA-4789).

3 Range of proton, number of neutrons produced per proton, and the linear production density of neutron in $w$ target.

4 Cell structure (1/16 of circumference), B-function and momentum compaction function.

5 R.F . cavity characteristics.

6 Conceptual layout of the experimental area for IPNS Facility. 
FEASIBILITY STUDIES OF AN ACCELERATOR

FOR THE INTENSE PULSED NEUTRON SOURCE (IPNS)

by

Tat K. Khoe and Motoharu Yimura

SYNPOSIS

A proton linac plus synchrotron system was studied for the proposed Intense Pulsed Neutron Source (IPNS) at Argonne. An Alvarez $\mathrm{H}^{-}$linac of $70 \mathrm{MeV}$ and a high intensity fast cycling proton synchrotron to accelerate protons to $800 \mathrm{MeV}$ will be the best choice to give a flux of $10^{26}$ thermal neutron/sec $\mathrm{cm}^{2}$ at the surface of moderator with a spallation neutron target of $W$ or $U^{23 \theta}$.

\section{INTRODUCTION}

The ubject of the Intense Pulsed Neutron Source (IPNS) is to scudy condensed materials (static and dynamic structures and also radiation effects) by means of very intense pulsed neutron beams at levels not attainable by steady-state reactors. Production of spallation netstrons by proto.ns accelerated up to about 500 to $1000 \mathrm{MeV}$ hitting a heavy metal target is the best way using current technology.

In the past the synchrotron has generally been considered as a low intensity machine. However, the use of $\mathrm{H}^{-}$injection makes it possible to build a high intensity synchrotron, for example, of 10 times higher current than the Booster II injector of the 7C.S. The high intensity synchrotron of medium energy ( $500-1000 \mathrm{MeV}$ ) has not been much explored in the past, mainly because of lack of demand for such a machine. The synchrotron requires as an injector a 50-100 MeV 1: nac with $\mathrm{H}^{-}$ion current of 10-20 mA.

\section{GENERAL LAYOUT OF ZING AND IPNS FACILITY}

The ZING facility which has already been discussed in detail ${ }^{1}$ is essentially a time sharing machine using the protons accelerated to $500 \mathrm{MeV}$ by the Booster II which will be built in the near future for the ZGS. The expected thermal neutron flux (peak value) is about $1.5 \times 10^{25} \mathrm{n}_{\mathrm{Th}} / \mathrm{sec} \mathrm{cm}^{2}$ using depleted $U$ as the target for spallation evaporation neutron production.

The capability of ZING for research on condensed materials will be enormous utilizing its thermal and epithermal pulsed neutron fluxes. Espectally, the expected epithermal flux will be one to three orders of magnitude larger than those obtainable by reactors. Some outlines were already discussed at the ZING Workshop on Apri1 29-May 4, 1973, and summarized in a report. ${ }^{2}$ The usefulness as well as future potential were also vertfied at many laboratories. ${ }^{3}$ 
It is widely recognized that the present intensity of the neution beams obtainable from steady state reacturs is far below the leve1 of femand. And It is technically very difficult as well as financlally not feasible to bulld a steady state reactor which may deliver a thermal neutron flux of $10^{16} \mathrm{n}_{\mathrm{Th}} / \mathrm{sec} \mathrm{cm}^{2}$. Therefore, the construction of an accelerator for this purpose should be considered.

The Canadian project "IN:", which has unfortunately been stopped, could have been one of the facilitles to accomplish this purpose, but was however designed to produce continuous neutron beans. The duty factor required for the pulsed neutron source of our present project is very low and the average power 18 roughly 0.001 of the power needed for the "ING" project.

In what follows we shall call the $\mathrm{H}^{-}$linac-proton synchrotron combination to produce pulsed nizutron beams, High Intensity Synchrotron (HIS), and the whole facility Intense Pulsed Neutron Source (IPNS).

For the efficient usage of the spectrometers and the experimental areas to be constructed for the IPNS, the accelerator complex should be installed close to the ZGS site.

\section{REQUIRED SPECIFICATIONS FOR THE IPNS}

\section{(a) Neutron Flux}

Upgrading to 10 times of ZING,

Peak thermal flux at the moderator surface,

$1 \times 10^{16} \mathrm{n}_{\mathrm{Th}} / \mathrm{sec} \mathrm{cm}^{2}$. pulse width $\leftrightharpoons 30 \mathrm{usec}$, up to 60 pulses per sec.

Peak epIthermal flux,

$2 \times 10^{16} \mathrm{n} / \mathrm{cm}^{2} \mathrm{sec} \mathrm{eV}$ at $1 \mathrm{eV}, 2-30 \mathrm{\mu sec}$, up to $60 \mathrm{pulses}$ per aec.

Total fast neutrons,

$1 \times 10^{15} n_{f}$-pulse, pulse width $\leq 1$ usec, up to 60 pulses per sec.

Time average fast neutron flux,

$10^{14}-10^{15} \mathrm{n}_{\mathrm{f}} / \mathrm{cm}^{2} \mathrm{sec}$ at energies in excess of $0.1 \mathrm{MeV}$ (close to the target).

Pulse width of accelerated protons must not be larger than 1 usec. 
(b) Other Kequirements

Cryosiat to cool the moderator down to liquid helium temperatures should be relat ively easy to install. The fast neutron producing source should be compact. Otherwise the above mentioned level of slow neutron flux will not be attainable. The target assembly must be sturdy, and easily serviced. The level of contamination by electron and positron, $X$ or gamma rays should be sufficiently low.

The neutron flux between the pulses should be very low at least less than $10^{-5}$ of those during the pulse.

IV. SOME CONSIDERATIONS ON POSSIBLE SYSTEMS OTHER THAN THAT PROPOSED IN THIS REPORT

\section{(a) 7.ING-Fission Neutron Multiplication System}

It is almost impossible to increase substantially the proton current and/or energy of the Booster II for the ZING.

To meet the increasing demand of upgrading neutron flux to at least ten times of the 2ING value, neutron multiplication by a fast subcritical assembly which will surround the target, would be necessary. However, the fission density and rate required to supply such a high flux of neutrons becomes considerably high, and the heat production rate will be of the order of $0.35 \mathrm{MW} / 11$ ter in the core, and the total power around $4 \mathrm{MW} .{ }^{4}$ It is a well established fact that the heat removal capacity of the core structure can exceed this level in the fast breeder reactor. However, in the present case, even though the total heat production rate is approximately $4 \mathrm{MA}$, there are two other factors which must be considered. First, very high flux density is required which is not necessarily required in FBR core. The core must also have a high atomic density of fuel material and be as compact as possible. Secondly, the thermal and inertial shock expected to be produced by the extremely sharp $r$ ise and fall of the fission reaction has not yet been fully analyzed, notwithstanding the considerable research and development work done. ${ }^{5-9}$

There exist some more drawbacks beside the just mentioned technical incertainty. First, though the background flux is very low, the integrated background neutrons produced between pulses due to the delayed neutron emission will reach a considerably high level $(n 9 \%)$ as compared to the useful neutrons in the pulse and this for many measurements would be the ratio of background to signal. This might give some trouble in very precise measurements. Secondly, the CTR radiation effect research requires a very high intengity fast neutron flux (preferably $14 \mathrm{MeV}$ ) for fusion reactor studies. Fast neutrons of these energy ranges can be produced efficlently by the spallation reaction, but not by the fission reaction. Further, an important class of radiation effects measurements requires the lowest possible ratio of gamma ray flux ta neutron flux. Spallation neutron production is much more attractive this way than fission production. Therefore, the addition of a fission neutron multiplying system will not contribute 
very much for the upgrading of the radiation ef fects research ctpability. Thirdly, the potential hazard to environment due to the fissisu products must be considered, even though the quantities expected in such a small core are far below those of the usual power reactors. The multiplying system is a subcritical assembly of the nuclear fuel. The maintenance procedure will be more elaborate and the maintenance cost will be substantially higher than those for particle accelerators.

\section{(b) Some Other Accelerators, etc.}

Because the final technical limitation is always encountered with the problems of heat removal capability, photoneutron production by any powerful electron accelerator will be ruled out.*

The D-T Fusion reaction has a large reaction cross-section to produce $14 \mathrm{MeV}$ neutrons, but the neutron flux obtained from these devices (rotating target, etc.) are several orders of magnitude smaller than needed here. A synchrocyclotron in the $800 \mathrm{MeV}$ range would have a lower peak current. A proton linear accelerator is a very powerful machine to produce intense neutrons. The LAMPF of LASL holds presently the capability to be the most intense neutron generator, provided it can produce the design average current of $1 \mathrm{~mA}$ and that all the protons will be solely used for the neutron production. However, the pulse length of the accelerated protons is $500 \mathrm{usec}$, far wider than can be tolerated for our requirement. This can only be shortened to the order of 1 usec if the proton beam is injected in a storage ring. A storage ring is a machine of much similarity with the synchrotron; the main difference being the constant magnetic field and the relatively low power of the constant frequency l..F. system. The construction and operation cost of a $800 \mathrm{MeV}$ linac-storage ring combination is certainly higher than that of a $800 \mathrm{MeV}$ fast cycling synchrotron and the $50-100 \mathrm{MeV}$ linac injector.

The linac on itself may be able to produce a narrow proton burst ( $\leq 1 \mu \mathrm{sec}$ ), but in this case to meet the intensity requirements the linac much accelerate an $8.0 \mathrm{~A}$ proton beam which is at least two orders of magn 1tude higher than presently achieved.

Another possibility is to accelerate deuterons instead of protons since the deuteron is the best particle for neutron production at low energy. However, in the spallation energy range there is little difference with protons of the same kinetic energy. If the energy per nucleon of the deuterons is the same as the energy of the protons, the deuteron may produce twice as much neutrons in spallation reaction in heavy metal targets. The number of spallation-evaporation neutrons produced per nucleon is roughly expressed by the following formula

$$
\mathrm{n} \approx(\mathrm{K}-120)(\mathrm{A}+20) \times 10^{-4}
$$

\footnotetext{
*Heat production per neutron is roughly in the ratio of 100:10:1 for photoneutron process, fission process and for nuclear spallation process.
} 
where $n=$ number of neutrons produced per incident nucleon

$K=k$ inett: energy of nucleon in $\mathrm{MeV}$

$\Lambda=$ (arget mass number, with target dimenston assumed to be, dfameter $10.2 \mathrm{~cm}$, length $61 \mathrm{~cm}$ target material (Be-Pb).

For a $U^{239}$ target the relation is given by

$$
n=2(K-120)(A+20) \times 10^{-4} \text {. }
$$

Thus deuteron acceleration is not advantageous if the total kinetic energy Is the same as that of the proton.

Suppose we build a new linac, the parameters of which will be optimized for deuteron acceleration investing the same amount of construction cost as for protons. The total length of the resonator tank $w^{4} 11$ be the same. The injection energy of the deuteron will be twice that of the proton but the final energy is the same. The deuteron synchrotron needs magnets producing larger fields or having larger radius because of the apprurimately $\sqrt{2}$ times larger momentum of the deuteron of the same kinetic energy as the proton. At the same energy per nucleon, the deuteron monentum would be twice that of the proton.

Thus the acceleration of deuterons is not very attractive even if we take into consideration the higher neutron production density along the particle path in the target (cf., Sec. V.a).

The future fusion reactor, if it is feasible, will be a very iatense neutron source. However, only the pulsed fusion reactor may satisfy the specification outlined in Sec. III. Furthermore, the realization of these fusion reactors appears to be very remote.

\section{PROPOSED H" LINAC-PROTON SYNCHROTRON SYSTEM}

\section{(a) Neutron Producing Target and Choice of Acceleration}

To attain the required peak flux $\hat{\phi}$ of slow neutrons at the surface of the moderator of $1 \times 10^{16} \mathrm{n}_{\mathrm{Th}} / \mathrm{sec} \mathrm{cm}^{2}$, the number of fast neutrons reaching the core-facing suriace of the moderator must be about $1 \times 10^{12} \mathrm{nf} / \mathrm{cm}^{2}$ pulse, in the configuration as shown in Fig. $1 .^{1}$

The spallation-evaporation neutron production density $\rho$ in the target, the neutron spectrum and the angular distributions were Monte-Carlo calculated at LASL for a proton beam of $800 \mathrm{MeV}, \mathrm{U}^{23 \mathrm{~B}}, \mathrm{~Pb}$ and $\mathrm{Ta}$ targets of $(10-20) \mathrm{cm}$ diameter and $(10-30) \mathrm{cm}$ long. ${ }^{11}$ For $800 \mathrm{MeV}$ protons on $U^{238}$, exponential decrease of $\rho$ is seen and the $1 / \mathrm{e}$ length along the proton path is $12.3 \mathrm{~cm}$ which is the high energy nucleon mean free path in $U$, whereas the proton range of $800 \mathrm{MeV}$ in $\mathrm{U}^{238}$ is $24 \mathrm{~cm}$. Figure 2 shows one of the results obtained at LASL. Beyond $24 \mathrm{~cm}$, neutron production decreases below the exponential decay. 


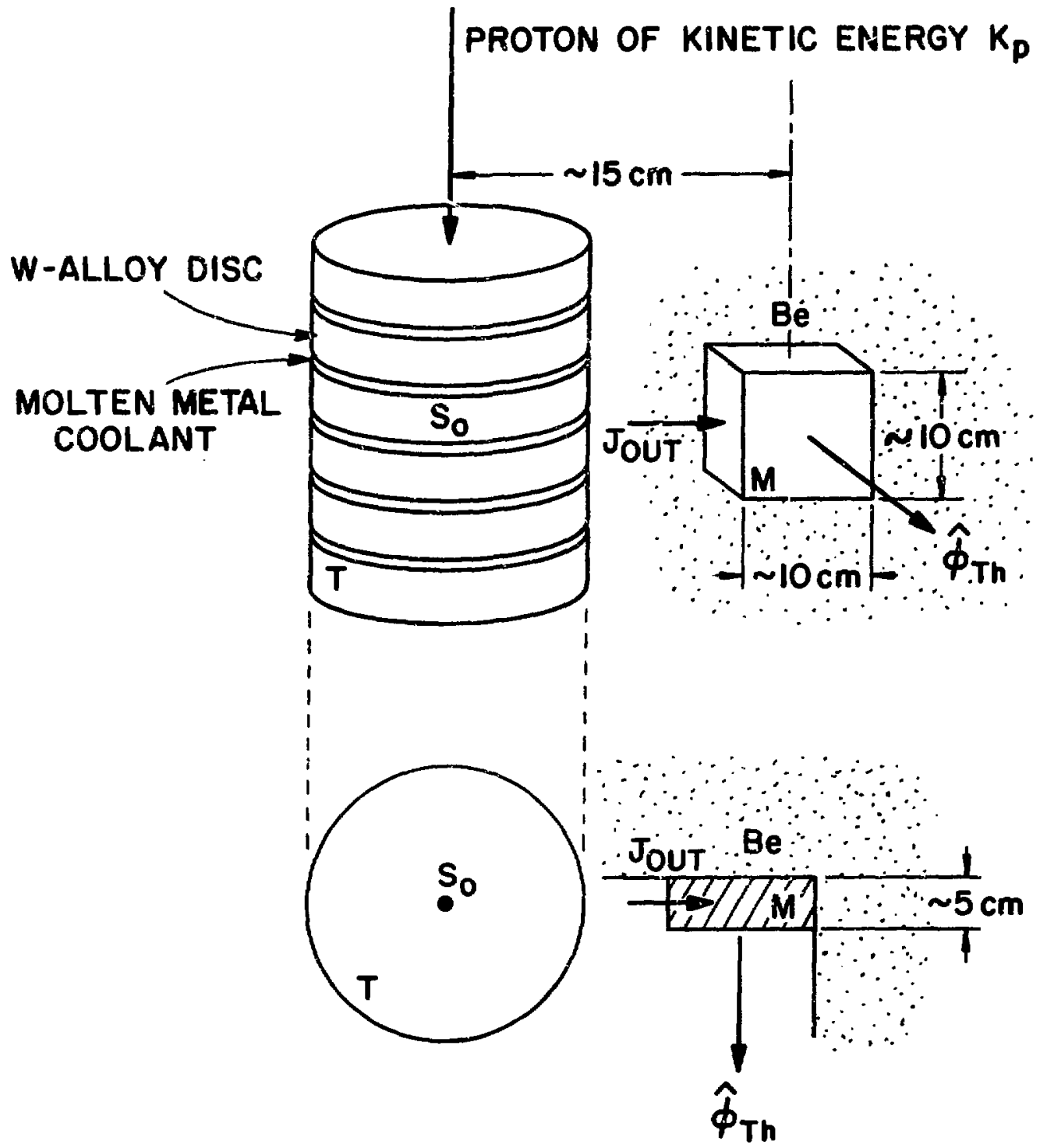

$M=\left(\mathrm{CH}_{2}\right)_{\mathrm{n}}$ moderator $(\sim 10 \mathrm{x} \sim 10 \mathrm{~cm} \mathrm{x} \sim 5 \mathrm{~cm})$

$\mathrm{Be}=\mathrm{Be}$ metal reflector surrounding the moderator

Fig. 1. Conceptual target and moderator assembly. 


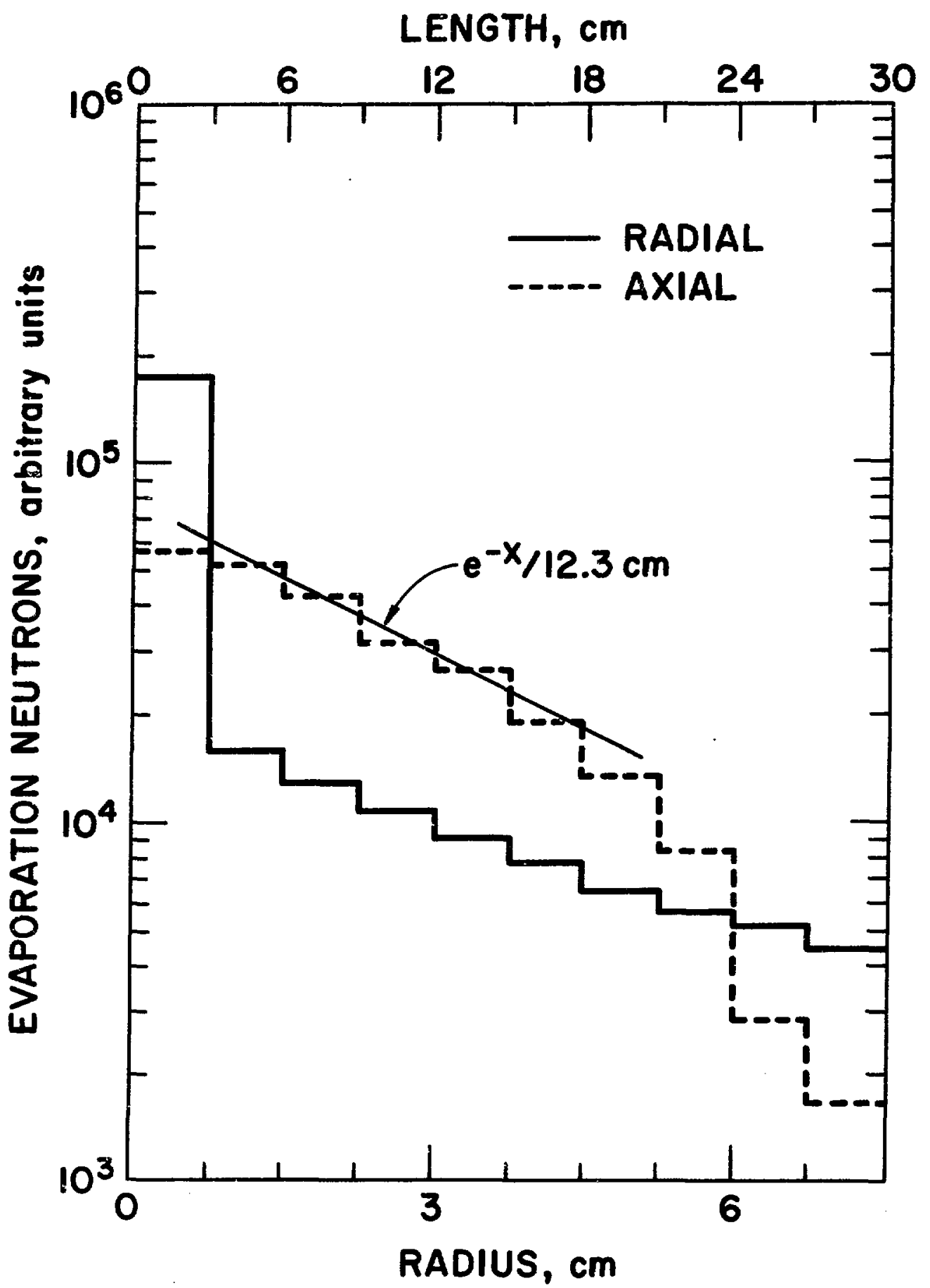

Fig. 2. Radial and axtal distribution of the production of evaporation neutrons in a $7.5 \mathrm{~cm}$ radius, $30 \mathrm{~cm}$ long $\mathrm{U}^{238}$ target with $800 \mathrm{MeV}$ protons incident on axis (LASL Report LA-4789). 
As the size of the moderator is not required to be very much larger than $10 \mathrm{~cm} \times 10 \mathrm{~cm} \times 5 \mathrm{~cm}$, a region of the highest neutron production density of $15 \mathrm{~cm}$ will be sufficient.

Table I. The range of proton and deuteron of several energies in some metals.

\begin{tabular}{ccccc}
$\begin{array}{c}\text { Energy of Proton } \\
\text { or Deuteron }\end{array}$ & Range & $\mathrm{W}(\rho=19.3)$ & $\mathrm{Pb}(11.5)$ & $\mathrm{U}(18.7)$ \\
\hline $500 \mathrm{MeV}$ & $\mathrm{R}_{\mathrm{p}}(\mathrm{cm})$ & 11.7 & 19.5 & 12.2 \\
& $\mathrm{R}_{\mathrm{d}}$ & 7.6 & 12.7 & 7.8 \\
$800 \mathrm{MeV}$ & $\mathrm{R}_{\mathrm{P}}$ & 23.2 & 39.0 & 24.0 \\
& $\mathrm{R}_{\mathrm{d}}$ & 16.7 & 28.0 & 17.2 \\
$1000 \mathrm{MeV}$ & $\mathrm{R}_{\mathrm{P}}$ & 31.7 & 53.5 & 32.8 \\
& $\mathrm{R}_{\mathrm{d}}$ & 23.5 & 39.3 & 24.2 \\
\hline
\end{tabular}

Table I summarizes the ranges of protons and deuterons for several particle energies and target materials. As seen in this Table the shorter range of a deuteron beam results in a more localized neutron production as compared to protons of the same energy.

Figure 3 shows the number of neutrons produced in $W$-target per proton together with the range of proton and linear neutron production density. Comparing this with the ZING project estimate ${ }^{1,9}$ for $500 \mathrm{MeV}$ proton incident on $a u^{238}$ target we obtain

$$
\frac{\mathrm{n}(800 \mathrm{MeV}+\mathrm{W})}{\mathrm{n}\left(500 \mathrm{MeV}+\mathrm{U}^{238}\right.} \approx 0.8
$$

Acceleration to more than $800 \mathrm{MeV}$ is not recommendable.

The thermal neutron flux obtainable at the moderator surface depends critically on the configuration of target-reflector-moderator assembly. A cooling system for target as well as moderator is required and the moderator efficiency is not always the same as in the case of low intensity model measurements. Using $W$ target instead of $U^{238}$ and a proton energy of $800 \mathrm{MeV}$, $4.0 \times 10^{13}$ protons per pulse at the target will be required to obtain $1 \times 10^{16} \mathrm{n}_{\mathrm{Th}} / \mathrm{sec} \mathrm{cm}^{2}$ during the pulse from the surface of moderator. Assuming $80 \%$ for the acceleration efficiency, $5.0 \times 10^{13}$ protons/pulse at injection will be needed. Effects of the proton beam emittance and energy spread will be discussed later. More accurate Monte Cario calculations of slow neutron fluxes are now being pursued by S. G. Das, J. M. Carpenter, and R. E. Prael. 


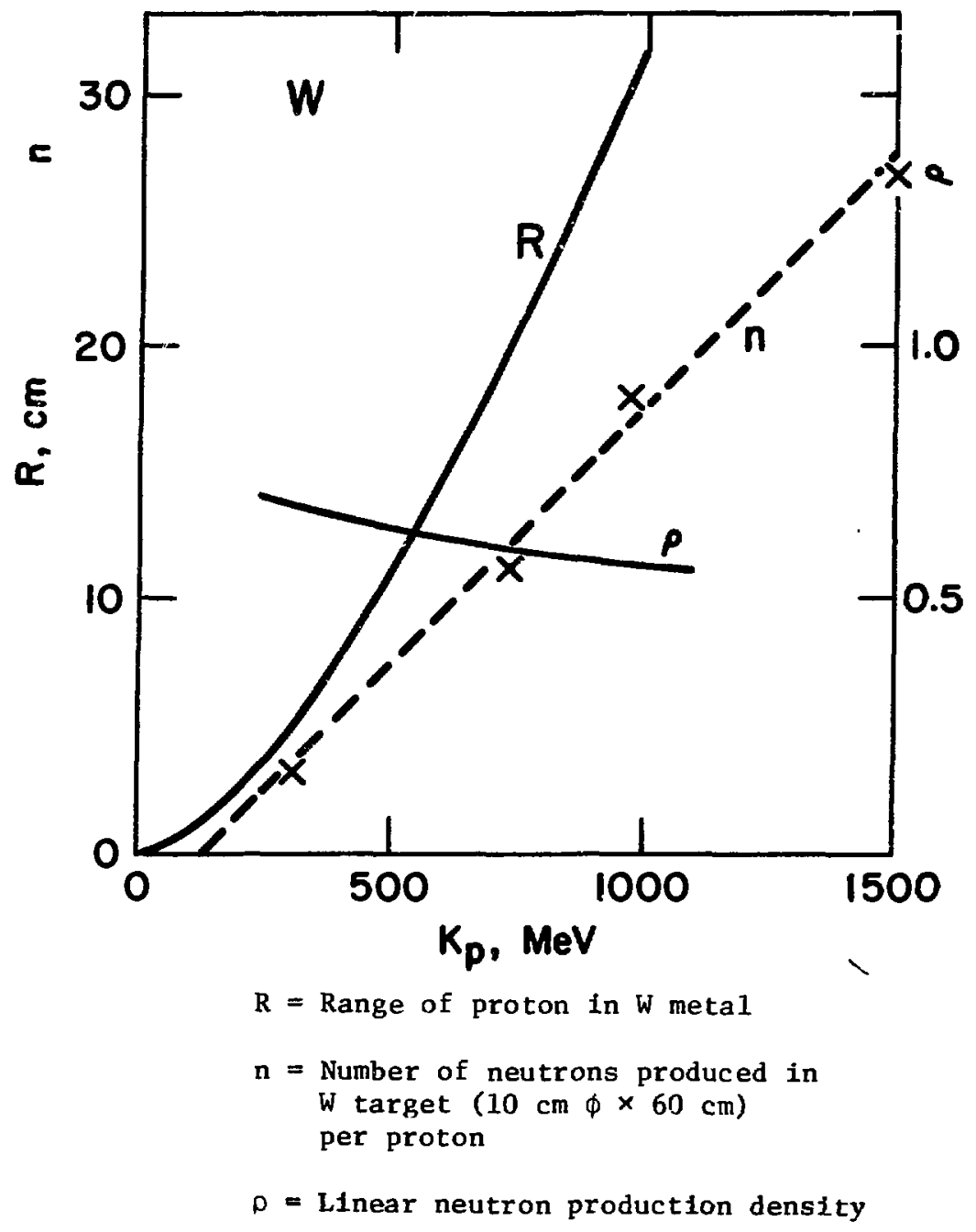

Fig. 3. Range of proton, number of neutrons produced per proton, and the linear production density of neutron in $\mathrm{W}$ target. 
In actuality, high energy protons of $500-800 \mathrm{MeV}$ will evoke fission process in the target materlal heavier than $T h$, whereas, spallation evaporation is the main process in the target like $\mathrm{W}$ or $\mathrm{Pb}$. The total cross-section for both processes is of the same order of magnitude, reaching $1.5 \sim 2$ barns.

The long living induced radioactivity expected in these targets will amount to the orcer of $10 \sim 30 \mathrm{mCi}$ per gram of the target material, after long irration period and after waiting for one day for cooling off in both of fission and spallation process. The proposed target assembly of about $20 \mathrm{kG}$ of $\mathrm{W}$ or $\mathrm{U}^{238}$ w11 be activated to the order of $1 \mathrm{KCi}$ after one day coollng following one week irradiation. Long living fission products such as $\mathrm{Sr}^{90}$ or $\mathrm{Cs}^{137}$ will be produced in lesser amount than in the case of low energy proton bombardment, whereas long life radio isotopes produced by spallation are not necessarily in small quantity.

The neutron yield in $U^{238}$ is almost twice larger than in $W$ and the heat generation per neutron in the former is about 1.7 times higher than in the latter.

The average kinetic energy of spallation neutrons is much higher than that of fission neutrons, and thus the $W$ target is more useful for the radiation effect study.

The merit or demerit of $W$ vs. $U^{238}$ is very close. It may be more safe to assume a $\mathrm{W}$ target at the present stage of design study.

\section{(b) Intensity Limitation in the Synchrotron}

\section{Space Charge Limit}

The space charge forces between a particle and the beam modify the effective focusing force and make the betatron frequencies intensity dependent. The beam intensity must be less than a value that would shift the betatron frequency to the nearest harmful resonance. In the IPNS synchrotron, as in most other accelerators, the vertical dimension of the beam is smaller than the horizontal dimension and the space charge limit is determined by the allowable vertical betatron frequency shift. For a beam of elliptical cross-section with horizontal axis $W$ and vertical axis $H$. the space charge Iimit is given by

$$
N=\frac{\pi H(H+W) \nu_{v} \Delta v_{v} B^{2} \gamma^{3} B F}{4 r_{p} R},
$$

where $v_{v}$ is the vertical betatron frequency, $\Delta v_{v}$ is the allowable shift in $v_{v}, r_{p}$ is the classical proton radius $\left(r_{p} \approx 1.54 \times 10^{-18} \mathrm{~m}\right), R$ is the mean radius of the synchrotron, $B$ is the bunching factor given by $B=$ (bucket area/ $2 \pi$ bucket height) and $F$ is a factor determined by the image charge and current. 


$$
F=\frac{1}{1+\frac{H(W+H)}{H_{g}^{2}}\left[\varepsilon_{1}\left(1+B \gamma^{2} B^{2}\right)+\varepsilon_{2} B \gamma^{2} B^{2}\left(\frac{H g}{G}\right)^{2}\right.}
$$

where $\mathrm{H}_{\mathrm{g}}=$ vertical vacuum chamber gap, $\mathrm{G}=$ magnet gap. For a beam between two parallel plates at a distance $\mathrm{H}_{\mathrm{g}_{13}}$ satisfying the condition $\mathrm{H}_{\mathrm{g}} \gg \sqrt{\mathrm{W}^{2}-\mathrm{H}^{2}}$ the image coefficients are given by ${ }^{13}$

$$
\varepsilon_{1}=\frac{\pi^{2}}{48} \text { and } \varepsilon_{2}=\frac{\pi^{2}}{24}
$$

In general the coefficients $\varepsilon_{1}$ and $\varepsilon_{2}$ are smaller than the values given above. The beam envelope varies in dimension along the circumference of the synchrotron

$$
\mathrm{H}=2 \sqrt{\beta_{\mathrm{v}} Q_{\mathrm{v}}} \text { and } \mathrm{W}=2 \sqrt{B_{h} Q_{h}}
$$

where $\beta_{v}$ and $\beta_{h}$ are respectively the vertical and horizontal betafunctions (Sec. V.c). $\pi Q_{v}$ and $\pi Q_{h}$ are the vertical and horizontal phase space areas occupled by the beam. In the IPNS synchrotron we find

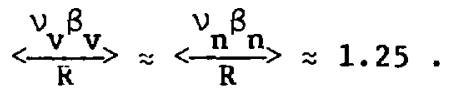

On the other hand, for $(W+H) H \approx H_{g}^{2}=G^{2}$ and $B=0.45$ we find for the image factor $F \approx 1 / 1.25$. The expression for the space charge limit reduces to

$$
N=\pi \frac{Q_{v}+\sqrt{Q_{v} Q_{h}}}{r_{p}} \Delta_{v} \beta^{2} \gamma^{3} B
$$

The phase space areas occupied by the beam must be smaller than the acceptance of the synchrotron

Vertical acceptance $\quad A_{V}>\pi Q_{V}$

Horizontal acceptance $A_{h}>\pi Q_{h}$.

For $N=5 \times 10^{13}, Q_{v}=1 / 2 Q_{h}, \Delta v_{v}=0.25, B^{2} \gamma^{3}=0.166$ (70 MeV injection) and $B=0.45$ we have

$$
Q_{v}=5.5 \times 10^{-4} \mathrm{rad}-\mathrm{m}, Q_{h}=11 \times 10^{-4} \mathrm{rad}-\mathrm{m}
$$




\section{Collective Instabilities}

The beam in the IPNS synchrotron is continuous during the injection. The synchrotron operates below the transition energy, therefore, no negative mass effect will occur. The growth rate of the spontaneous bunching due to resistive walls and/or inductive walls is of the order of milliseconds or longer, while the total injection time is only $850 \mu \mathrm{sec}$. Therefore, it is not likely that spontaneous bunching will occur during the injection.

For the same reason we may expect that the transverse instabilities will not be serlous during the injection.

The bunched beam longitudinal instability must also be considered. The simplest coherent mode is the dipole rigid bunch motion (i.e., harmonic oscillation of the bunch center with respect to R.F. phase). For a smooth circular vacuum chamber the growth rate for a single bunch is given by ${ }^{14}$

$$
\frac{1}{\mathrm{~T}}=0.0134 \Omega_{s} \frac{\left|\mathrm{Z}_{\mathrm{s}}\right| \mid}{\mathrm{V} \cos \phi_{s}} \mathrm{I} G\left(\nu_{s}\right),
$$

where

$$
\Omega_{s}=\frac{\omega_{0}}{\beta} \sqrt{\frac{|\eta| \mathrm{eV} \cos \phi_{s}}{h 2 \pi \mathrm{E}_{s}}}
$$

is the synchrotron frequency, $Z \|$ is the coupling impedance, $V$ is the peak accelerating voltage, $\phi_{\mathbf{S}}$ is the synchronous phase, $h$ is the harmonic number, $E_{S}$ is the total energy of the synchronous particle and $n=1 / \gamma_{t}^{2}-1 / \gamma^{2}$. $\left(\gamma_{t}=\right.$ transition energy in units of $m_{o} c^{2}, \gamma$ particle energy in units of $\left.m_{0} c^{2}.\right)$ The function $G\left(\nu_{\mathrm{S}}\right)$ is gjven by

$$
\begin{aligned}
& G\left(\nu_{s}\right)=\sum_{k=1}^{\infty} \frac{\sin 2 \pi k \nu_{s}}{k^{5 / 2}}, \nu_{s}=\frac{\Omega_{s}}{\omega_{0}} \\
& \omega_{0}=\text { particle angular velocity. }
\end{aligned}
$$

The coupling impedance is approximately given by

$$
z_{\|}=\frac{2 \pi R}{G}(1+i) R_{s} .
$$

$R_{s}=\left(\omega_{0} \mu \mu_{0} / 2 \sigma\right)$ is the surface resistivity, where we have assumed that the pole tips are the vacuum chamber walls; $\mu$ and $\sigma$ are respectively the permability and conductivity of the wall material. In the IPNS synchrotron just after capture we find $\left|z_{\|}\right| \approx 13 \mathrm{ohm}, v \cos \phi_{\mathrm{s}} \approx 3 \mathrm{kV},|\mathrm{n}|=0.8, \mathrm{~h}=2$ 
and $v_{S} \approx 1.2 \times 10^{-3}$. It is not difficult to show that $G\left(v_{S}\right) \ll 1$ so $1 / \tau \ll 2.6$ or $\tau \gg 380 \mathrm{msec}$. In reality the wall is not circular and smooth but the growth rate is so large compared to the acceleration time that we may expect that the bunched beam resistive wall instability can be ignored. The rotation frequency, moreover, changes by a factor 2.3 during the $8.3 \mathrm{msec}$ acceleration time that we may expect that the bunched beam resistive wall instability can be ignored. The rotation frequency, moreover, changes by a factor 2.3 during the $8.3 \mathrm{msec}$ acceleration time. For the same reason we can neglect the inductive wall effect.

Bunched Beam Transverse Instabilities

In the bunched beam there are two classes of transverse instabilities; namely, the rigid bunch instability and the head tail instability. The choice of $k<v<k+1 / 2$ insures for a single bunch stability against the resistive wall effect. However, dipole coherent instability can occur due to ions in the residual gas. The proton bean will ionize the molecules of the residual gas. In general the electrons have enough energy to escape to the vacuum chamber walls in a time interval short compared to the rotation period of the beam. Since the beam is bunched, capture of the electrons in the potential well of the proton is not possible.

The effect of the ion cloud can be suppressed by the introduction of an octopole field which provides Landau damping for the coherent oscillations. A servo system will also be used. These methods have been applied successfully in several accelerators.

The Head Tail Instability

The betatron frequency $v$ and the angular velocity $\omega_{0}$ depend on the momentum of the particle. Therefore, the betatron phase difference between a nonsynchronous and the synchronous particle changes as the nonsynchronous particle moves from the head to the tail of the bunch or vice versa. The amount of this phase shift is given by

$$
\chi=\frac{1}{2} \Delta\left(w_{0} t_{s}\right)
$$

where $t_{s}$ is the synchrotron oscillation period. The angular velocity $\omega_{0}$ averaged over the period $t_{s}$ is the same for all particles of the bunch. Thus

$$
\left.\Delta\left(\omega_{0} t_{s}\right)=\Delta \omega_{0} t_{s}+\omega_{0} \Delta t\right)=0
$$

Substitution of this in the expression for $\chi$ gives

$$
x=\frac{1}{2} \Delta\left(v \omega_{0} t_{s}\right)=\frac{1}{2}\left(\frac{d v}{d p} \Delta p\right) \omega_{0} t_{s} .
$$

Using the relations: 


$$
\therefore=\frac{d v}{d p} \frac{p}{v} \quad \text { (the chromaticity) }
$$

and

$$
\eta=\frac{1}{\gamma_{t}^{2}}-\frac{1}{\gamma^{2}}=-\frac{d \omega_{0}}{d p} \frac{p}{\omega_{o}},
$$

we obtain

$$
x=-\frac{1}{2} \frac{\xi}{n} v(\Delta \omega)_{\delta} t_{s}=\frac{\xi}{n} t_{l},=\frac{1}{2} \frac{\xi}{n} v \omega_{0} \Delta t_{s}=\frac{\xi_{2}}{n} v \omega_{0} t_{l}
$$

where $t_{\ell}=(1 / 2) \Delta t_{s}$ is the bunch length in secouds. For small values of $X$ it can be shown ${ }^{15}$ that the growth rate can be written in the form

$$
\frac{1}{\tau}=k \times
$$

where the quantity $K$ is the positive or negative depending on the mode number. However, for zero chromaticity $X=0, F_{3}=0$ and regardless of the mode number

$$
\frac{1}{\tau}=0 \quad \text { oi } \tau=\infty
$$

Therefore, sextupole magnets to correct the chromeicity must be included in the Jesign.

\section{(c) The Choice of the Lattice Structure}

The cell structure periodicity $N$ and the betatron frequency $\nu$ should be chosen to avoid operation close to serious resonances. The maximum betatron function $B_{\max }$ which determines the magnet aperture should be as small as possible. This requirement implies the choice of large $N$ and $v$, but a large value of $N$ reduces the length of each straight section. As a compromise the following cell structure has been chosen. The number of cell pertods $N=16$; the betatron frequencies are $v_{h}=4.25$ and $v_{v}=5.25$. The 16 straight sectlons are each $2.5 \mathrm{~m}$ long to allow sufficlent space for R.F. cavities, kicker and septum magnets, coherent oscillations damping system, etc. To accomodate the high intensity beam the synchrotron acceptance and therefore the apertures of the dipole and quadrupole magnets must be large. To keep the power loss within a reasonable value a maximum bending field of $6 \mathrm{kG}$, and a maximum gradlent of $0.5 \mathrm{kG} / \mathrm{cm}$ are chosen. The increase of the synchrotron circumference due to the low field choice is negligible compared to the straight section length required for the R.F. cavities, etc. Figure 4 shows the cell structure and the computed betafunctions and momentum compaction function for the following parameters 


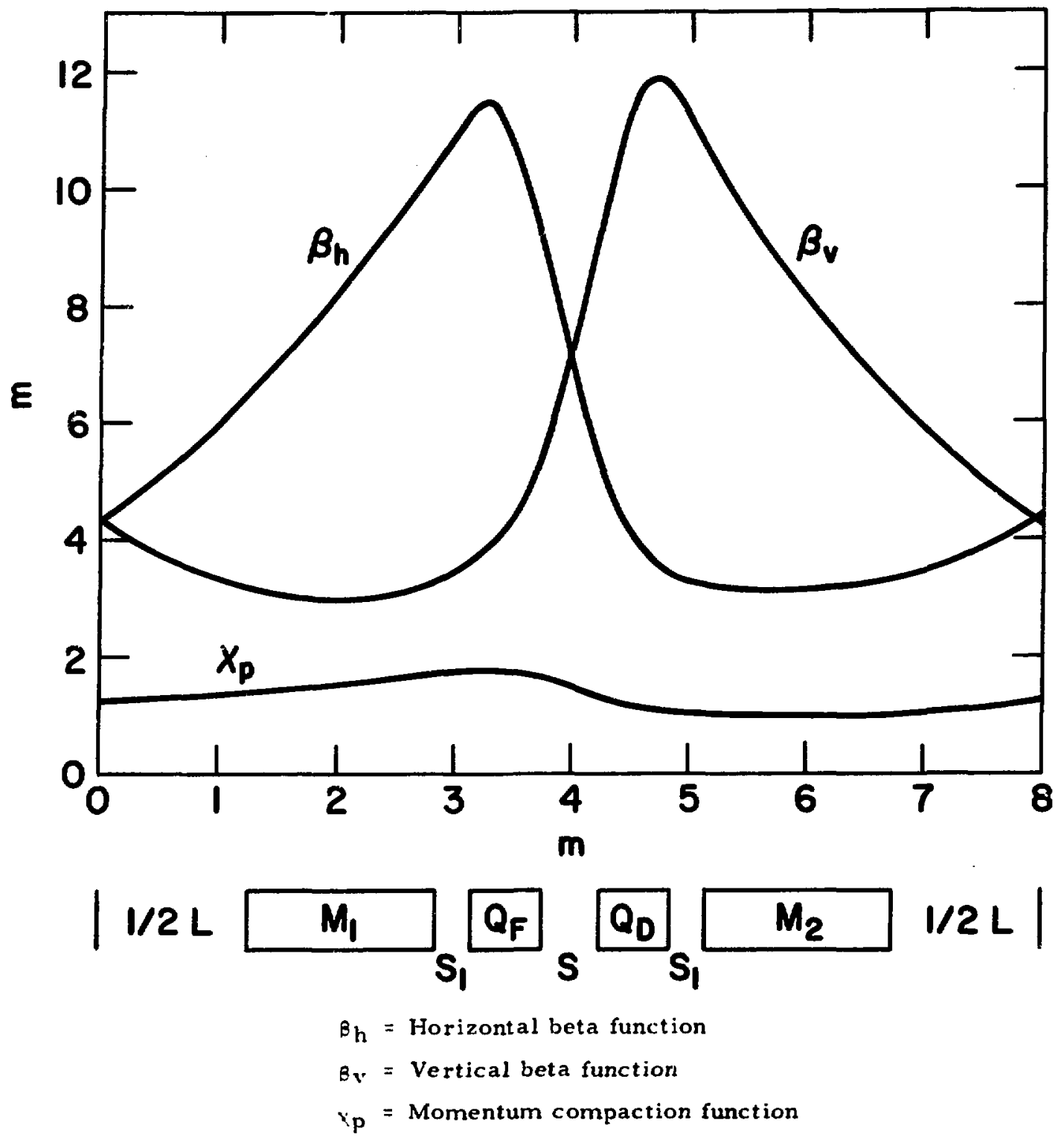

F18. 4. Ce11 structure (1/16 of c1rcumference), $\beta$-function and momentum compaction function. 


$$
\begin{aligned}
L & =2.5 \mathrm{~m} \\
M_{1} & =M_{2} \approx 1.6 \mathrm{~m} \\
S_{1} & =0.3 \mathrm{~m} \\
S & =0.5 \mathrm{~m} \\
Q_{F} & =Q_{D}=0.6 \mathrm{~m}
\end{aligned}
$$

For better versatility a separated function magnet system is chosen.

(d) The Choice of the Injection Method ( $\mathrm{H}^{-}$versus $\mathrm{H}^{+}$) and the Injection Energy

The $\mathrm{H}^{-}$injection in a synchrotron increases the beam intensity because we can take advantage of the better betatron amplitude distribution and longer injection time. The maximum number of turns for $\mathrm{H}^{+}$injection in a strong focusing synchrotron cannot exceed 30 turns, whereas injection of $\mathrm{H}^{-}$ can last for 700 turns or longer.

The longer rotation period for a smaller injection energy reduces the current requirement of the $\mathrm{H}^{-}$source to a level which gives reliable operation. On the other hand a low injection energy results in a larger beam size if the space charge limit is fixed. The final choice of the injection energy should be a compromise, taking into account cost, extraction problems, source development, etc. The required $\mathrm{H}^{-}$current $\mathrm{I}$, the maximum vertical beam height $\mathrm{H}_{\max }$ and the horizontal beam quality $Q_{h}$ at $800 \mathrm{MeV}$ are summarized in Table II as a function of the injection energy $E_{i}$ for a space charge limit $\mathrm{N}=5 \times 10^{13}, 700$ turns injection with $70 \%$ efficiency and the beam quality ratio $Q_{h}=2 Q_{v}$.

TABLE II

\begin{tabular}{lllllll}
$E_{i}$ & 30 & 50 & 70 & 90 & 100 & $\mathrm{MeV}$ \\
$\mathrm{I}$ & 9.6 & 12.3 & 14.3 & 15.9 & 16.6 & $\mathrm{~mA}$ \\
$\mathrm{H}_{\max }$ & 25.3 & 19.3 & 16.2 & 13.9 & 13 & $\mathrm{~cm}$ \\
$\mathrm{Q}_{\mathrm{h}}$ & 43.8 & 33.1 & 27.4 & 23.6 & 22 & $\mathrm{mrad}-\mathrm{cm}$ \\
\hline
\end{tabular}

Table II shows that the beam size and therefore the required magnet aperture decreases with increasing injection energy. On the other hand the $\mathrm{H}^{-}$ current increases with the injection energy. For this feasibility study we choose tentatively an injection energy of $70 \mathrm{MeV}$. The required $\mathrm{H}^{-}$current $I=14.3 \mathrm{~mA}$ is about 5 times the current injected in Booster I. This extrapolation seems within the reach of the present state of the technology of the $\mathrm{H}^{-}$source. If in the future it turns out that higher $\mathrm{H}^{-}$beam could be produced, an increase of the injection energy to 90 or $100 \mathrm{MeV}$ may be advantageous. 
(e) The Injection and Extraction Methods

The bending magnetic field varies with time as

$$
B=B_{1}+\frac{1}{2}\left(B_{e}-B_{1}\right)(1-\cos \Omega t)
$$

where

$$
\begin{aligned}
B_{1} & =1.573 \mathrm{kG} \\
B & =6 \mathrm{kG} \\
\Omega & =120 \mathrm{~m} / \mathrm{sec} .
\end{aligned}
$$

The injection of $\mathrm{H}^{-}$will be started at $t=-850 \mu \mathrm{sec}$, lasting to $t=0$ when the magnetic field reaches the minimum value $B_{i}$. At the start of the injection the equilibrium orbit is located $8.5 \mathrm{~cm}$ inside of the center of the vacuum chamber, i.e., $\Delta R=-8.5 \mathrm{~cm}$. The $\mathrm{H}^{-}$injection stops when the equilibrium orbit reaches the center of the vacuum chamber $(\Delta R=0)$. The stripper foil will be installed on the periphery of a rotating disk, the axis of which will be horizontal and at the inner side of the synchrotron donut. A steering magnet with a sawtooth shaped field will sweep the injected $\mathrm{H}^{-}$beam vertically over a distance of $\pm 4 \mathrm{~cm}$ to follow temporarily the motion of the stripper foil. Initially, due to its betatron motion, the proton will traverse the foll once in every 4 turns. When the equilibrium orbit expansion is larger than the size of the foil, the proton will miss the foil entirely. For example, if the foil width is $2 \mathrm{~cm}$, the protons make on the average approximately 50 traversals during the injection pulse. The vertical steering of the beam will distribute the beam over the avallable vertical acceptance of the synchrotron. The change in the magnetic fleld during the injection spreads the beam over the horizontal phase space. A more detailed orbit calculation may be needed to obtain the total number of traversals for each injection process.

If we assume 50 traversals for all the injected protons, the total number of traversals will be $2.5 \times 10^{15}$ per pulse or $1.5 \times 10^{17}$ per second. If we assume $10^{20}-10^{21}$ traversal $/ \mathrm{cm}^{2}$ before the foll is destroyed, the life will be $0.5-5$ hours for a foll of approximately $3 \mathrm{~cm}^{2}$ ef fective area. The number of folls on the disk determines the servicing interval of the stripper system. Some research and development may be necessary to find a better stripper material and method.

Extraction of the $800 \mathrm{MeV}$ protons will be in a single turn using a kicker magnet and a septum magnet. The septum magnet should be located one sector downstream of the kicker magnet, which is located downstream of $\mathbf{M}_{2}$. As the phase advance of the betatron oscillation per sector is given by $\sigma_{x}=v_{x} 2 \pi / N=\pi / 2$, the beam displacement and divergence at one sector downstream is Biven by

$$
\Delta x=\beta_{x} \sin \sigma_{x} \theta, \Delta x^{\prime}=\left(\cos \sigma_{x}-\alpha_{x} \sin \sigma_{x}\right) \cdot \theta
$$


where $\beta_{X}$ is the horizontal betafunction value at the location of the kicker (septum) magnet, $\alpha_{x}=-1 / 2 \beta_{x}^{\prime}$, and $\theta$ is the amount of the deflection due to the kicker magnet. $X$ The injected beam is approximately $16 \mathrm{~cm}$ wide at the location of the septum magnet. Assume the septum is 10 cated at $\$ .25 \mathrm{~cm}$ from the center of the beam. Since the beam is approximately $8 \mathrm{~cm}$ wide at $800 \mathrm{MeV}$ $\Delta \mathrm{x}$ must be $8.25+8 / 2+$ septum thickness. For a $1 \mathrm{~cm}$ thick system we have $\Delta x=13.25 \mathrm{~cm}$. At the septum magnet $B_{x} \approx 4 \mathrm{~m}$ and we find

$$
\theta=\frac{\Delta x}{B_{x}} \simeq 0.033 \text { radian }
$$

which requires the kicker magnet strength

$$
B_{k} \ell_{k}=4.881 \times 0.033 \simeq 0.16 \text { Tesla-m }=1.6 \mathrm{kG}-\mathrm{m} .
$$

The rise tine $\Delta t$ of the kicker field must be shorter than half the R.F. pertod at $800 \mathrm{MeV}$. Assuming a harmonic number $h=2$ we find $\Delta t=0.125 \mu \mathrm{sec}$. The kicker voltage is given by

$$
v_{k}=\left|\frac{d \psi}{d t}\right| \simeq \frac{B_{k} l_{k} D}{\Delta t},
$$

where $\mathrm{D}$ is the width of the kicker magnet gap. At $800 \mathrm{MeV}$ the beam cross section at the location of the kicker magnet is $\sim(\pi / 4) 8.5 \times 6 \mathrm{~cm}^{2}$. Taking $\mathrm{D}=14.5 \mathrm{~cm}$ we obtain

$$
v_{k}=\frac{0.16 \times 0.145}{0.125 \times 10^{-6}}=186 \mathrm{kV}
$$

This voltage is rather high; it may be necessary to reduce the harmonic number or increase the injection energy. An $8 \mathrm{kG}-\mathrm{m}$ septum magnet with $1 \mathrm{~cm}$ entrance septum could guide the beam out of the synchrotron.

\section{(f) Magnet and Vacuum System}

The width of the bending magnets and the bore of the quadrupole magnets are determined by the required space for extraction. Some parameters of the magnets are given below 


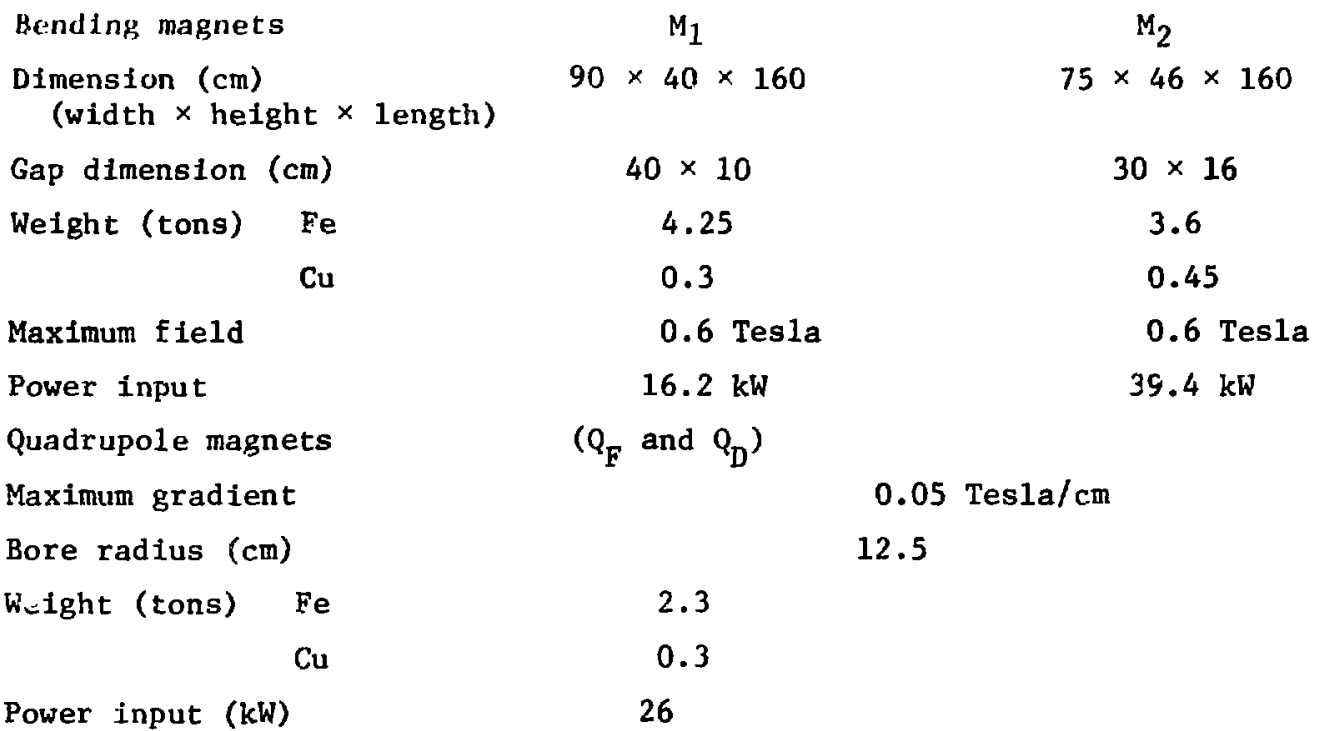

\section{Vacuum System}

Because of the high repetion rate the eddy current in the walls of a metal vacuum chamber would give an unacceptable field distortion. As in the Booster II, the pole tips will be a part of the vacuum chamber. The design pressure should be $5 \times 10^{-7} \mathrm{~mm} \mathrm{Hg}$ or better. Experience with Booster II may show that a better vacuum is necessary. A ceramic vacuum chamber is then required.

\section{(g) Accelerating System}

The most important feature of the R.F. system for the proposed synchrotron is the high power required to accelerate the intence proton beam. The design allows at least 8 straight sections, each $2.5 \mathrm{~m}$ long to accommodate the R.F. cavities. The choice of the harmonic number will be determined by the kicker voltage limitation and R.F. power requirement. In the meantime, a harmonic number of $h=2$ is tentatively chosen. The cavities must be excited in the appropriate phase reiations, that is

$$
v_{i}=v_{m i} \sinh \left(\omega t-\phi_{i}\right)
$$

where $v_{m i}=$ peak voltage of cavity $i$

$$
\begin{aligned}
\omega & =\text { angular velocity of proton } \\
\phi_{i} & =\text { phase of cavity } i
\end{aligned}
$$


The required phase relationships between the cavities are easily maintained. The required energy gain per turn is given by

$$
\begin{aligned}
\mathrm{eV}_{\mathrm{a}} & =\mathrm{e} \sum_{\mathrm{i}} \mathrm{V}_{\mathrm{mi}} \sin \phi_{\mathrm{si}}=2 \pi \mathrm{R} \rho \mathrm{e} \dot{\mathrm{B}} \\
& =\pi \operatorname{R} \rho \Omega \mathrm{e}\left(\mathrm{B}_{\mathrm{a}}-\mathrm{B}_{1}\right) \sin \Omega \mathrm{t} \\
& \approx 88 \sin \Omega \mathrm{t} \mathrm{KeV} .
\end{aligned}
$$

The maximum value of $88 \mathrm{KeV}$ will be reached when $t=4.17 \mathrm{msec}$. $\phi_{\mathrm{si}}$ is the synchronous phase angle of cavity $i$ and all $\phi_{\text {si }}$ should be about $30^{\circ}$. Figure 5 shows the required energy gain per turn and some related quantities during the acceleration period. The revolution frequency increases from $f_{i}=0.86$ $\mathrm{MHz}$ at injection to $\mathrm{f}_{\mathrm{C}}=1.97 \mathrm{MHz}$ at $800 \mathrm{MeV}$. The revolution frequency at $\dot{\mathrm{B}}_{\max }$ is $\mathrm{f}_{\mathrm{B}}=1.71 \mathrm{MHz}$ and the beam current at this instant is

$$
I=\mathrm{Nef}_{B}=5 \times 10^{13} \times 1.6 \times 10^{-19} \times 1.71 \times 10^{6}=14 \mathrm{~A}
$$

The peak power delivered to the beam is $P_{b}=I V_{a} \max =1.23 \mathrm{MW}$. Assume there are $8 \mathrm{R} . F$. cavities each with a shunt resistance $R_{c} \approx 5 \mathrm{~K}$ ohm and a peak voltage $V_{m i}=25 \mathrm{kV}$. The total R.F. peak power is then

$$
P_{\text {peak }}=8 \frac{V_{m i}{ }^{2}}{R_{c}}+P_{b}=2.23 \mathrm{MW}
$$

The R.F. power will vary as shown in Fig. 5, which is roughly proportional to $\dot{B}^{2}$. In Table III for comparison some quantities of the R.F. system of Booster II and the IPNS synchrotron are shown.

TABLE III

\begin{tabular}{lcc}
\hline & Booster II & IPNS Synchrotron \\
\hline Proton beam and repetition rate $5 \times 10^{12} \mathrm{ppp}, 30 \mathrm{~Hz}$ & $5 \times 10^{13} \mathrm{pPp}, 60 \mathrm{~Hz}$ \\
Max energy gain per turn & $10.5 \mathrm{KeV}$ & $88 \mathrm{KeV}$ \\
Beam current at B Bax & $2 \mathrm{~A}$ & $14 \mathrm{~A}$ \\
Peak beam power & $21 \mathrm{KW}$ & $1.23 \mathrm{MW}$ \\
Peak cavity loss & $\sim 120 \mathrm{~kW}$ & $1.0 \mathrm{MW}$ \\
Tota1 R.F. peak power & $\sim 141 \mathrm{~kW}$ & $2.23 \mathrm{MW}$ \\
\hline
\end{tabular}




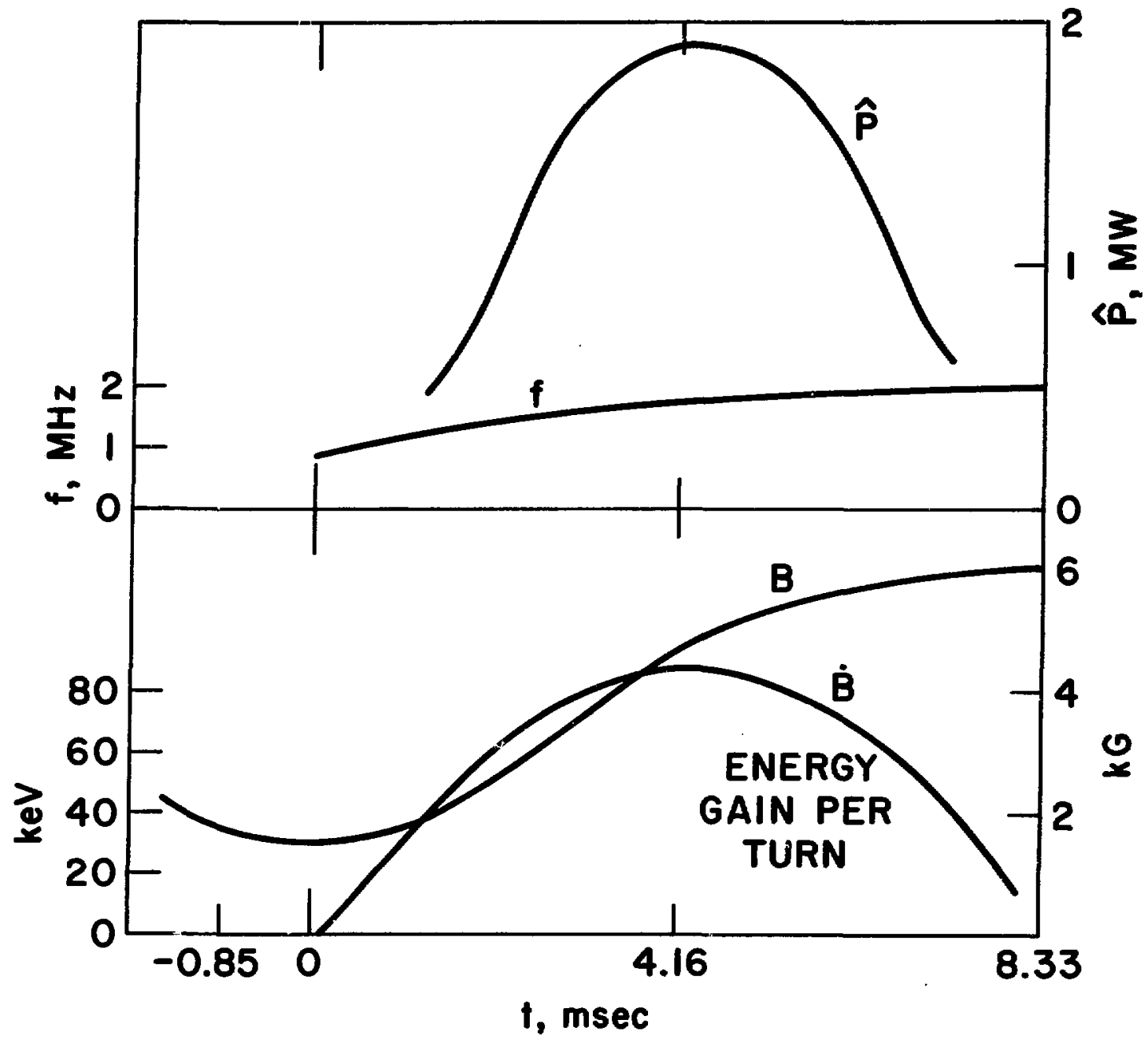

Fig. 5. R.F. cavity characteristics. 


\section{SHIELDING AND TRANSPORT SYSTEM}

An ideal accelerator will need no shielding because there is no loss of the accelerated particles. In practice, however, it is not possible to eliminate all the shielding. especially at the transfer of the particles from pre-accelerator to linac and from linac to synchrotron.

The IPNS accelerator complex should be located at the area north of the 12 foot bubble chamber. The conventional earth cover and concrete shielding should decrease the radiation hazard to an acceptable value. To reduce the effect of roof and skyshine, the location of the accelerator complex and the neutron experimental building should be at least $100 \mathrm{~m}$ apart. Skyshine interference of neutrons from accelerator to neutron experimental equipments must be carefully avoided since it is not expedient to cover the experimental area with heavy shielding. For the neutron scattering measurements it is important not to spill protons during the beam transport from the synchrotron to the neutron target system. The counting rate in almost all of the important inelastic scattering measurements is sometimes as low as several counts per minute. Even if we install heavy shielding around the spectrourter, we always must leave some holes for vacuum manifolds, cables, etc., which make it difficult to prevent the neutrons to get into the spectrometer.

Stray fast neutrons are also very troublesome. Shielding walls around the spectrometer sometimes increases instead of reducing the background because of the slowing down of these neutrons. A $0.1 \%$ proton beam loss at some point $20 \mathrm{~m}$ from the spectrometer will give a fast neutron flux of $\sim 10^{4} \mathrm{n}_{\mathrm{f}} / \mathrm{sec} \mathrm{cm}^{2}$ on the shielding wall of the measuring device, which will be enough to be a source of increasing background. Since the output proton beam of the synchrotron may have a momentum spread of the order of $0.3 \%$, an achromatic transport system (ATS) will be necessary.

One of the authors (M.K.) suggested the horizontal proton beam inlet for the ZING Facility because of its easiness of handling the target assemblies (neutron target and radiation effect target) and also of the reduction in construction expenses. It may also work for the IPNS. The experimental area will come out something like shown in Fig. 6 , in which the horizontally bent proton beam by ATS will reach the target through a rather long path. The beam pipe approaching the shielding facility should be covered by concrete shielding, and preferably made of thin Al pipe. The upstreaming neutrons through the proton beam hole will be well collimated. The $Q$ magnets which will be instalied in or outside of the shielding facility should have the bore radius larger than the neutron beam. In this way, we may be abie to secure a low neutron background in the experimental area. 

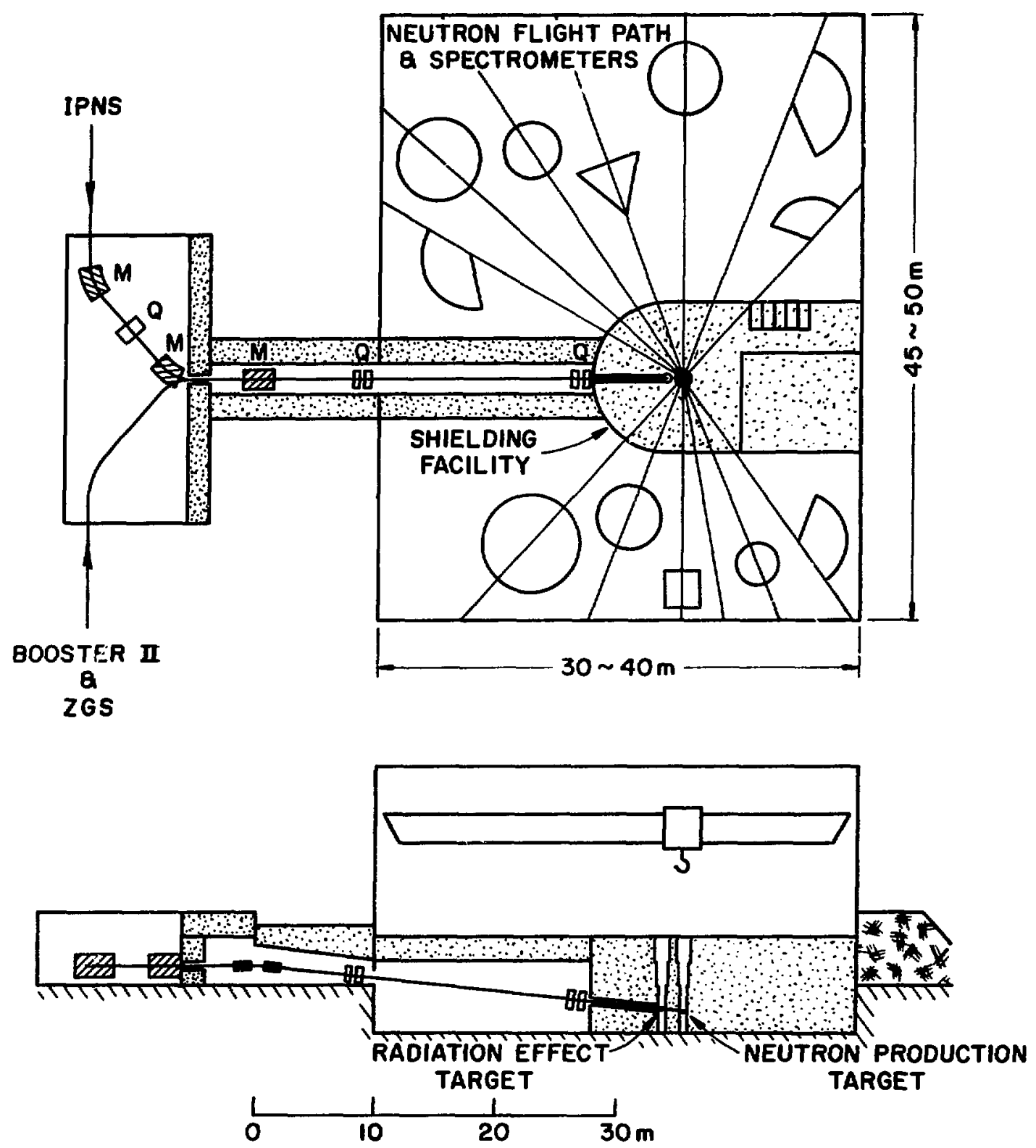

Fig. 6. Conceptual layout of the experimental area for IPNS Facility. 
Accelerator Parameters

a. Pre-accelerator-Cockcroft-Walton

Energy

$\mathrm{H}^{-}$current

b. Linear Accelerator

Energy

R.F. frequency

Number of cavities

Beam pulse length

Pulse rate

Duty facror

Total linac length

Beam current

Peak cavity excitation power

Total peak power

Emittance

Momentum spread $\Delta p / p$

c. Proton Synchrotron

Maximum kinetic energy

Intensity

Repetition rate

Injection energy

Injection current

Number of turns injected

Magnet radius

Average radius

Number of straight sections

Length of straight section

Number of periods

Structure of period

Betatron frequency

Horizontal

Vertical

Revolution frequency

Momentum compaction factor

$\beta_{\max }$ vertical horizontal

Beam emittance at $800 \mathrm{MeV}$

Horizontal

Vertical

Momentum spread at $800 \mathrm{MeV}$ : $\Delta p / p$

Bending magnet peak field Injection $f$ ield

Number of bending magnet

Length of bending maget
$750 \mathrm{KeV}$

$\geq 25 \mathrm{~mA}\left(\mathrm{H}^{-}\right)$

$800 \mathrm{MeV}$

$5 \times 10^{23}$ protions/pulse

$60 \mathrm{~Hz}$

$70 \mathrm{MeV}$

$14.5 \mathrm{~mA}\left(\mathrm{H}^{-}\right)$

700

$8.135 \mathrm{~m}$

$20.37 m$

16

$2.5 \mathrm{~m}$

16

OMOFODOMO

24.25

$\sim 5.25$

$0.86-1.97 \mathrm{MHz}$

0.06

$11.9 \mathrm{~m}$

$11.5 \mathrm{~m}$

$\pi 27.5 \mathrm{mrad}-\mathrm{cm}$

$\pi 13.8 \mathrm{mrad}-\mathrm{cm}$

$1.9 \times 10^{-3}$

$6 \mathrm{kG}$

$1.513 \mathrm{kG}$

32

$1.6 \mathrm{~m}$ 


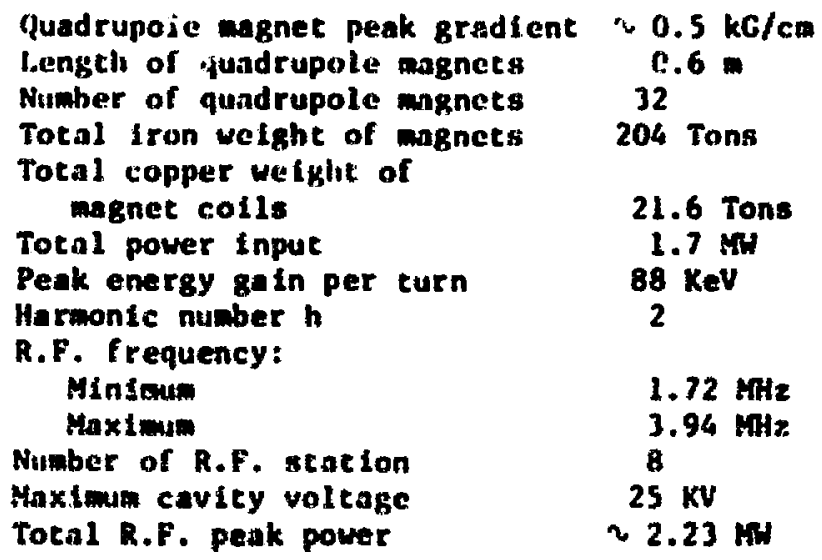

\section{ACKWONEDGHENT}

We wish to thank Dr. E. Crosbie for camputing the betafunctions and the momentum compaction funceson. One of the authors (H.K.) is grateful to Dr. David 1. Price, Ditector of the Solld Stace Science Division, co have given him a chance to stay at Ah, and to study the ZIKK Proje:t and to work on the design of the IPWS Facility. He is also grateful to the hospitality of all the staff of ANt., especially to the valuable suggestions of Dr. James D. Simpson of the acceleracor Research Factlitfes Division.

\section{REFERENCES}

1. J. M. Carpenter and 6. J. Marmer, Evaluation of the 265 Injectorbooster as an Intense Neutron Generator, NNL/SSS-72-1 (1972).

2. Applications of a Pulsed Spallation Neutron Soutce, Workshop Report (1973) ANL-B032.

3. Research Reports of the Laboratory of Nuclear Science, Tohoku University Vol 1 - (1967 - ), etc.

4. Some Considerations on ZIMG-Booster Systen Alaing $10^{16} \mathrm{nth} / \mathrm{sec} \mathrm{cm}^{2}$ or More for Thermal Neutron Flux, Motoharu KImura, September 1973; material not yet published.

5. K. C. Hof fman, R. Parsik, M. Reich, and M. Levine, Engineer Ing Problems in Pulsed Neutron Sources, BNL-104S4 (1966).

6. M. S. Farkas, Editor, Battelle Memorial Institute, Columbus, Ohio, Mechanical and Physical Properties of Fuels and Cladding Materials with Potential for Use in Brookhaven's Pulsed Fast Reactor, BMI-X455 (1967). 
7. J. M. Hendrie, K. C. Hoffman, H. J. C. Kouts, J. R. Parsik, J. P. Phelps, G. A. Price, M. Reich, H. Takahasıl, and H. H. Windsor, Brookhaven Pulsed Fast Research Reactor, BNL-13208 (1969).

8. Proceedings of the National Topical Meeting on Fast Burst Reactors, Albuquerque (1969).

9. P. J. Peralani, Computation of ZING-Booster (1974), private communtcation.

10. E. D. Courant, BNL Report 6511 (1962); Th. Sluyters, CERN Report 64-22 (1964); S. Ohmura and Th. Sluyters, 1972 Proton LInac Conference, p. 191; A. M. Bald1n, et al., JINR, Dubna, P9-5442 (1971); BNL-TR-431.

11. R. R. Fullwood, et al., Neutron Production by Medium-Energy Protons on Heavy Yetal Targets, LA-4789, IIC-34 (1972).

12. A. Suzuk1, ANL BI-19 (1969); BI-22 (1969); and also "Proposal for a $500 \mathrm{MeV}$ Booster Injector for the ZGS Synchrotron.

13. L. J. Laslett, Proceedings of the 1963 Summer Study on Storage Rings, Accelerators and Experimentation at Super-High Energies, p. 325.

14. F. J. Sacherer, Proceedings of the 1973 Particle Accelerator Conference, IEEE Trans. Nuc1. Sc1. NS-20 \#3, p. 825.

15. F. J. Sacherer, Proceedings of the IXth International Conference on H1gh Energy Accelerators (1974), p. 347. 